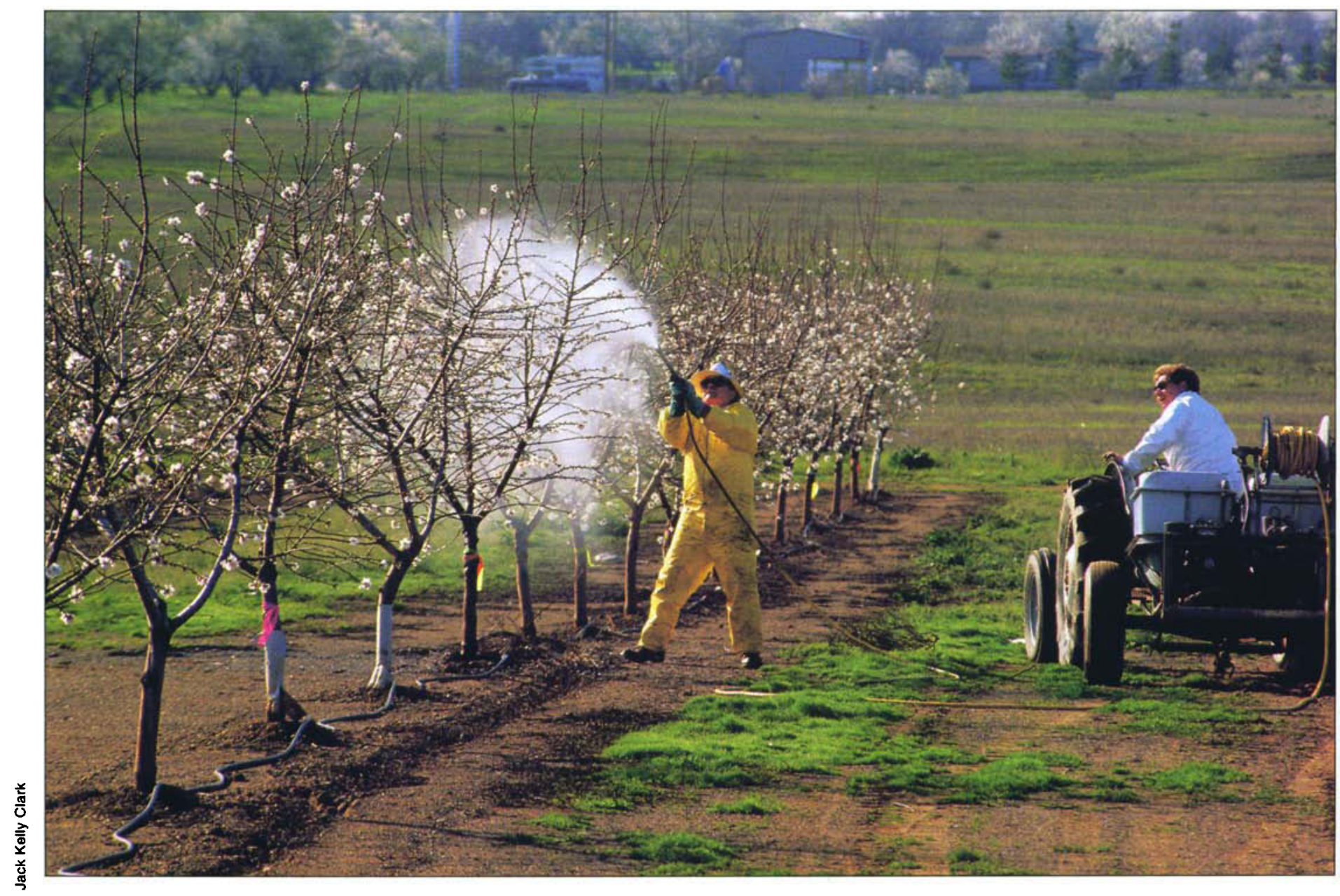

Instead of applying an organophosphate dormant-season spray, almond growers can monitor and treat only when pests are present. For the peach twig borer, one alternative is a bloomtime spray of the microbial agent Bacillus thuringiensis.

\title{
Almond and stone fruit growers reduce OP, increase pyrethroid use in dormant sprays
}

Lynn Epstein U Susan Bassein U Frank G. Zalom

Growers and pesticide applicators in California are legally required to file pesticide use reports with details about every application to commercial crops. We used the individual applicator records to document a decline in the use of organophosphate pesticides (OP) on almond and stone fruit orchards during the rainy season in California, a time period in which the trees are dormant. The decline is important because dormant applications are a major source of sur- face water contamination and the Federal Clean Water Act mandates a reduction in movement of OPs into surface water. However, the decline in use of OPs has been accompanied by an increase in use of pyrethroid pesticides, particularly in stone fruit orchards. Additional implementation of "reduced-risk" integrated pest management practices could further reduce use of dormant applications of OPs and pyrethroids on almonds and stone fruit orchards.
Tore than 750,000 acres of 1 almonds, nectarines, peaches, plums and prunes are grown in the Sacramento and San Joaquin valleys (fig. 1). During the 1970s and 1980s, a suggested component of an integrated pest management (IPM) program for these tree crops was to apply an organophosphate (OP) insecticide (e.g., diazinon, naled [Dibrom], phosmet [Imidan], methidathion [Supracide] or chlorpyrifos [Lorsban]), generally with oil, during the dormant season. Dormant sprays effectively control a complex of significant pests, particularly 
the peach twig borer (Anarsia lineatella) and the San Jose scale (Quadraspidiotus perniciosus). The application also controls two important aphids on plums and prunes: the leaf curl plum aphid (Brachycaudus helichrysi) and the mealy plum aphid (Hyalopterus pruni). The oil component of the application controls the European red mite (Panonychus ulmi) and the brown mite (Bryobia rubrioculus) on all of the orchard crops.

When the application of an OP during the dormant season was first introduced in the early 1970s, it was viewed as an environmentally sound practice, because one application during the dormant season potentially replaces multiple applications during the growing season (Rice et al. 1972). Also, an application of an OP during the dormant season has other environmental advantages over an in-season application: fewer adverse affects on beneficial arthropods, less exposure to field workers, and no exposure of fruit to potential residues. However, during the 1990s, in response to food safety concerns, regulators took a critical look at use of OPs. Carbamates (e.g., carbaryl [Sevin]) and OPs are targeted under the Food Quality Protection Act of 1996. In addition, federal and state regulatory agencies are particularly concerned about OP contamination of surface waters, such as streams and rivers. The OPs originate in part from dormant-season applications that are washed from almond and stone fruit orchards during winter rainstorms (Domagalski et al. 1997).

Research to determine alternatives to dormant-season OPs for almond and stone fruit orchards was initiated in 1990 (Barnett et al. 1993; Hendricks 1995). Use of the research results was promoted by UC Cooperative Extension advisors and specialists, and also by the Biologically Integrated Orchard Systems (BIOS) demonstration project. The first recommended alternative to dormant-season OPs is to monitor for pests, and treat only when the pest is present. For the peach twig borer, environmentally reduced-risk treatments may include any of the following: bloomtime sprays of the biocontrol agent Bacillus thuringiensis; a dormant, bloom or in-season application of

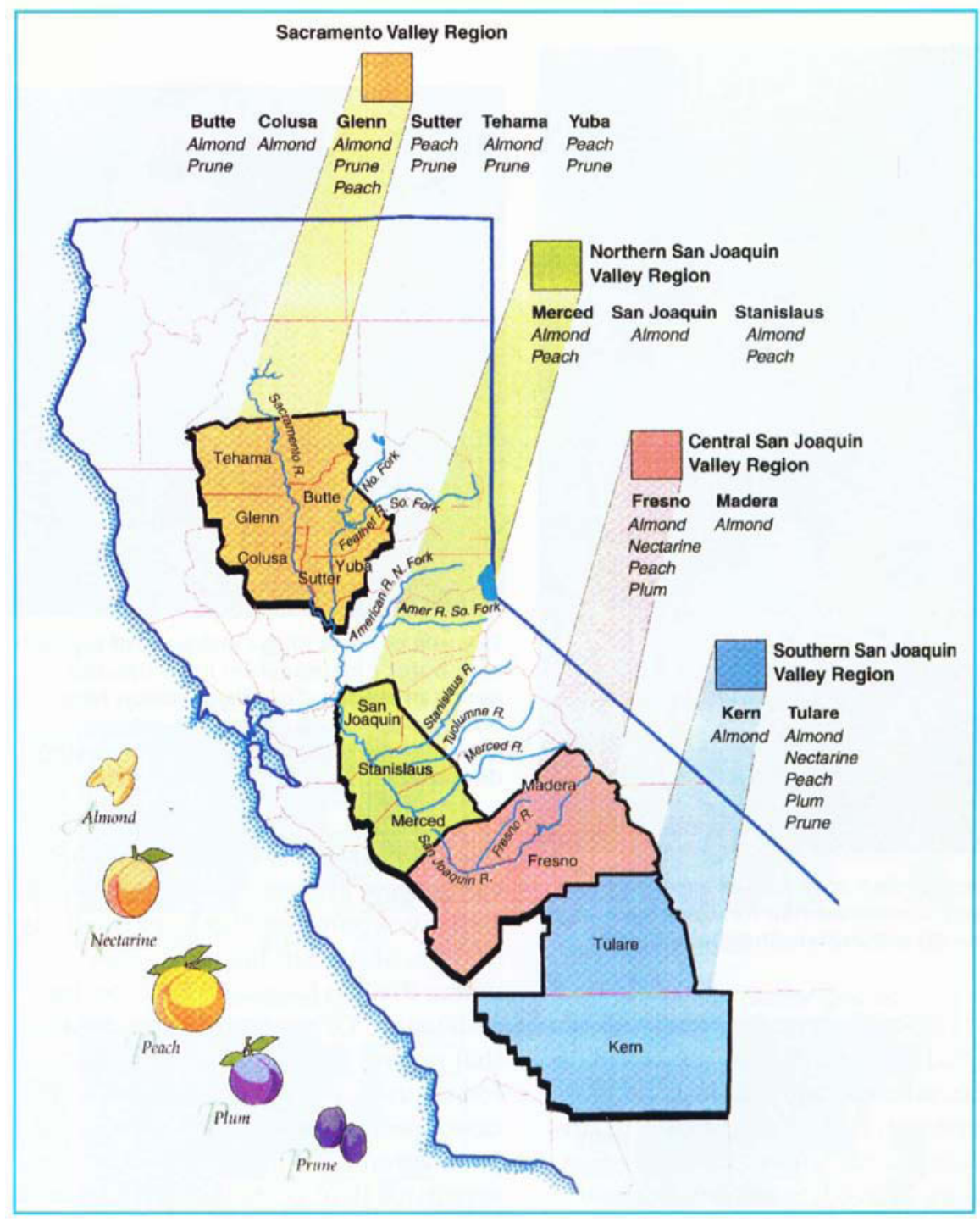

spinosad (Success); or in-season use of pheromones for mating disruption (Bentley et al. 1999; Zalom et al. 1998). To control San Jose scale, the reducedrisk treatment is a high rate of oil without another insecticide. Alternative practices for aphids on plums and prunes are currently being researched.

To control these pests, growers also can use either dormant or in-season applications of conventional pesticides that have a broad range of activity and are somewhat effective: either pyrethroids (e.g., permethrin [Ambush or Pounce] or esfenvalerate [Asana]) or in some instances carbamates. However, there are environmental risks associated with these materials. Dormant applications of pyrethroids and carbamates might also contribute to contamination of surface water. Furthermore, in areas of the Sacramento Valley, there is greatly increased tolerance of the peach twig borer to pyre-
Fig. 1. Counties in the Sacramento and San Joaquin valleys with at least 6,175 acres of either almond, nectarine, peach, plum or prune orchards. Regulators are concerned about the contamination of major rivers by dormant-season applications of organophosphates (OP).

throids, with some observed field failures. Also, residues of the pyrethroid insecticides permethrin and esfenvalerate persist on bark, and may impact beneficial arthropods for an extended period of time (Zalom et al. in press).

To comply with the Federal Clean Water Act, the California State Water Resources Control Board and the California Department of Pesticide Regulation (CDPR) are required to prevent and to respond to movement of OPs into surface water (Bennett et al. 1998). Toward this goal, the Regional Water Quality Control Boards instituted environmental monitoring and devel- 


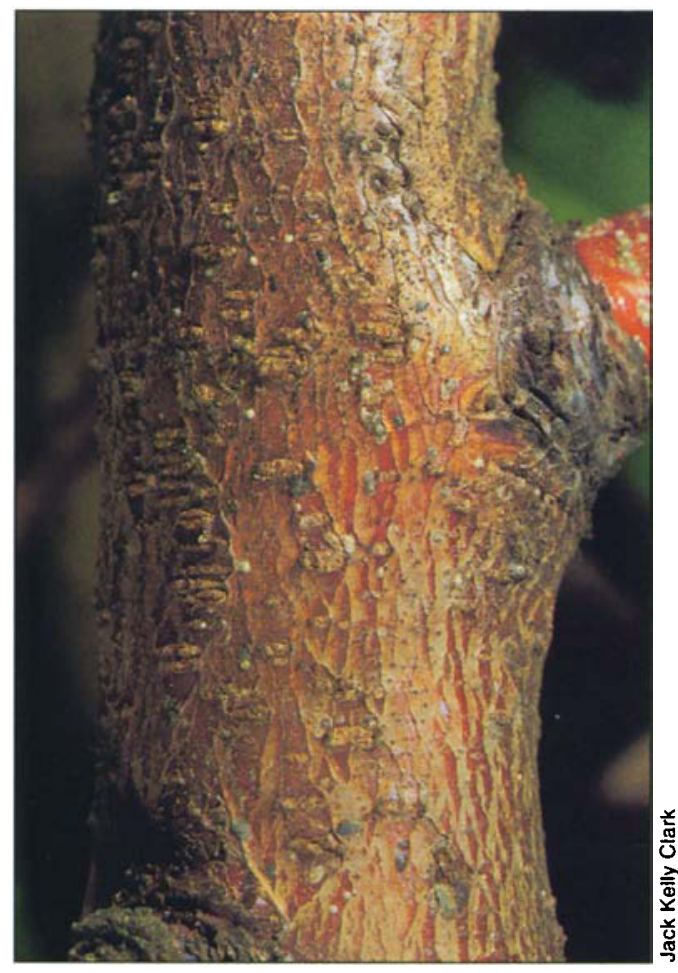

To control San Jose scale in the dormant season, a reduced-risk treatment is a high rate of oil without another insecticide.

oped regional plans. The Region $5 \mathrm{Wa}-$ ter Quality Control Plan is focused on the Sacramento and San Joaquin river watersheds, including the land draining into the Sacramento, Feather, San Joaquin, Merced, Stanislaus and Tuolumne rivers and their associated creeks and drains. This area includes the Sacramento Valley and the northern and central portions of the San Joaquin Valley (fig. 1).

The State Water Quality Plans have three tiers of implementation. In tier I growers are asked to voluntarily use best management practices to reduce movement of OPs into surface water. If the Regional Water Quality Control Boards deem it necessary, they have the authority to invoke the more stringent tiers. In tier II, regulators set water-quality goals and encourage use of best management practices. In tier III, regulators control effluent release. To date (October 2000), CDPR has asked growers to voluntarily take measures to reduce water contamination from OPs during the rainy season (Bennett et al. 1998). These measures include using best management practices for applying pesticides and preventing runoff, and adopting alterna-

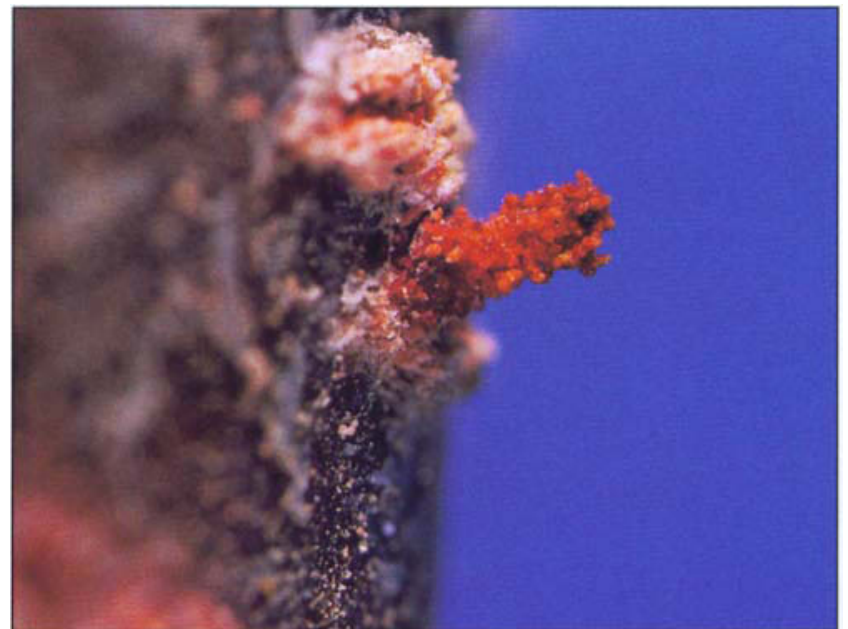

The pile of frass at the entrance of a peach twig borer hibernaculum indicates the pest's presence. To reduce peach twig borer populations during the season, growers can use pheromones for mating disruption.

tive IPM practices. There may be advantages to growers in switching to alternative control methods, particularly in parts of the San Joaquin Valley where the San Jose scale is becoming resistant to OPs. Also, to the extent that growers can monitor and then treat only in the years when it is indicated, reduced use of OPs may lower production costs if monitoring is less expensive than pesticide application.

\section{Applicator records}

In California, growers and pesticide applicators are legally required to file Pesticide Use Reports (PUR) with details about every application to commercial crops. We analyzed the orchard crops on which the largest quantity of OPs are applied on dormant orchards (almond, peach, prune, plum and nectarine) and the counties with at least 6,175 acres of these tree crops (fig. 1). When indicated, we have presented data only for selected counties in the Sacramento Valley (figs. 2 and 3 ) and in the northern and central San Joaquin Valley because use of dormant-season OPs in the southern San Joaquin Valley is of less immediate concern to regulators.

We retrieved all individual application records from CDPR from 1990 to 1998 on the selected crops. Data were processed with SAS (Cary, NC) software. Despite using data-cleaning soft- ware, the 1990 and 1991 data were too unreliable to use (Epstein et al. in press). Consequently, we used 1992 as the first year of our study, except for two county-crops (Butte County almonds and Stanislaus County peaches) in which the data were not of suffi춯 cient quality until 1993. For this study, pyrethroids, carbamates and endosulfan were classified as "other chemicals." $B$. thuringiensis, spinosad and oil applied without an insecticide were classified as "reduced-risk" alternatives. Pheromones were not included here as a reduced-risk material because it is generally used in-season. In addition, although there may be underreporting of pheromone use in the PURs, the overall use of pheromones for peach twig borer mating disruption at any time of year was very low during the study period.

In this paper, the "rainy season" coincides with the "dormant season," that is, the dormant period in which chemical treatments are applied plus the bloom period in which either $B$. thuringiensis or spinosad are applied. We considered the "rainy season" to be from Dec. 10 to March 20. Although the actual rainy season starts during the autumn in California, treatments with OPs on the dormant plants do not commence until mid-December because leaves typically remain on the trees at least until this date.

We computed the relative percentage of planted acres that were treated with either OPs, other chemicals, reducedrisk materials, or were untreated during the dormant season. Data also was examined on a per-grower basis. Results on a per-grower basis were comparable to the data shown here that are on a per-area basis.

We calculated the total pounds active ingredient of OPs applied per acre of crop for each year in each county using two methods. In the first method, we summed all records. Be- 


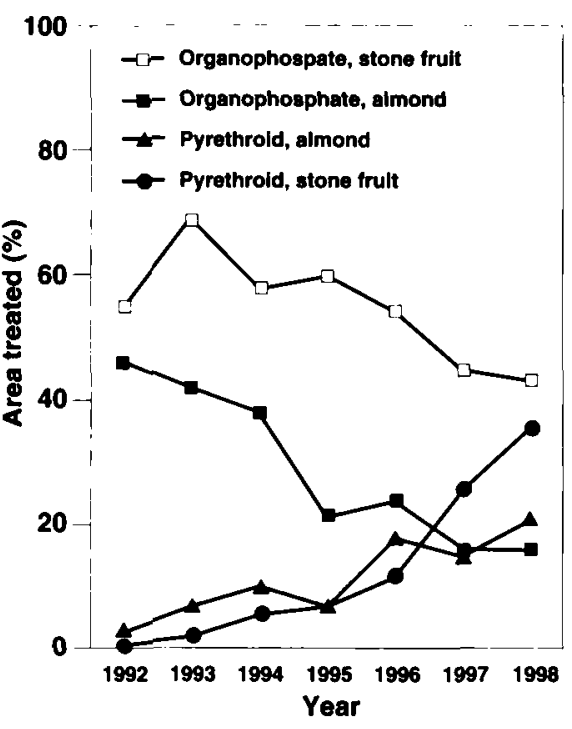

Fig. 2. Percentage of area treated during the dormant season with OPs and pyrethroids in almond and stone fruit orchards, 1992 to 1998, including orchards in counties in the Sacramento Valley and northern and central San Joaquin Valley with at least 6,175 acres of almond, peach, prune, plum or nectarine.

cause a sum is vulnerable to a few gross errors in a small number of records, we also computed a somewhat biased but very robust estimate of the total pounds of OPs based on a median application rate. We first computed the median application rate per county for each of the OPs. Then for all sites in each county, we multiplied (acres treated) by (median application rate in pounds of active ingredient per acre in that county in that year). Then the calculated pounds of all the active ingredients was summed. The values obtained using the median application rates were reasonably close (within $12 \%$ ) of the values obtained by summing in 53 of the 54 (98\%) countycrop-period combinations. The calculated sums are cited in this paper.

To minimize the impact of annual fluctuations in OP use due to weather conditions or changes in pest densities, we averaged the data in the early years of the study (1992 to 1994) and the final 3 years of the study (1996 to 1998). For each of the selected countycrops, the percent change in annual OP use during the later period in comparison to the earlier period was calculated.
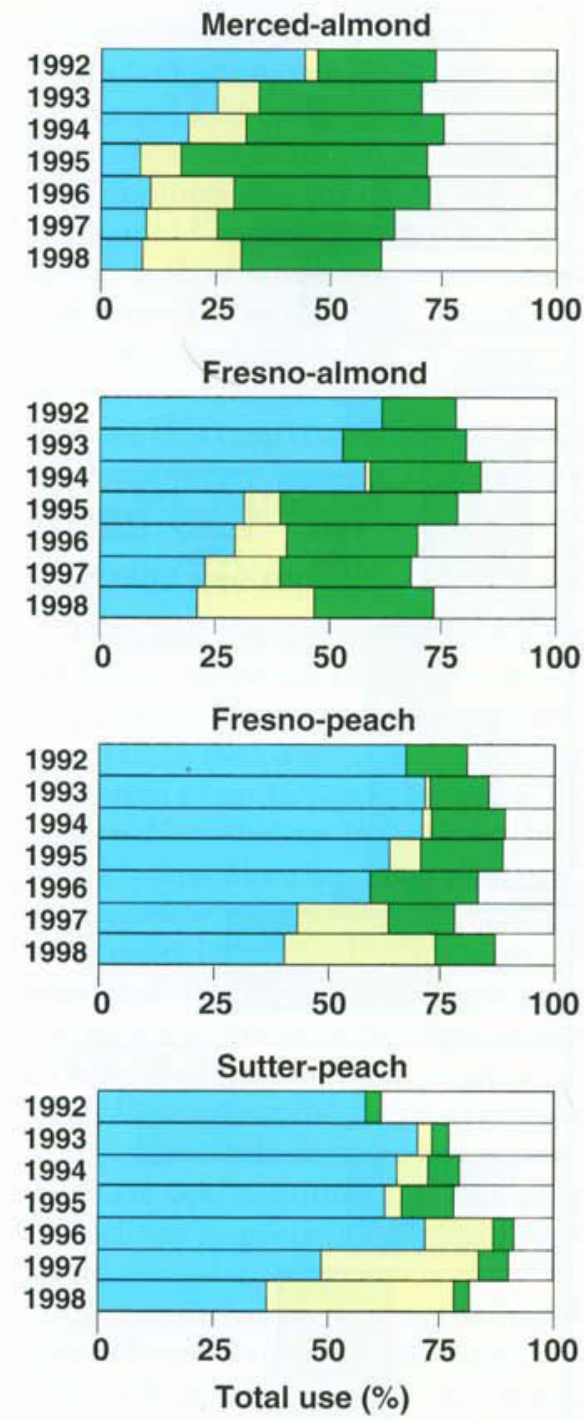

\section{Organophosphates \\ Other chemicals \\ "Reduced-risk" products \\ No treatment}
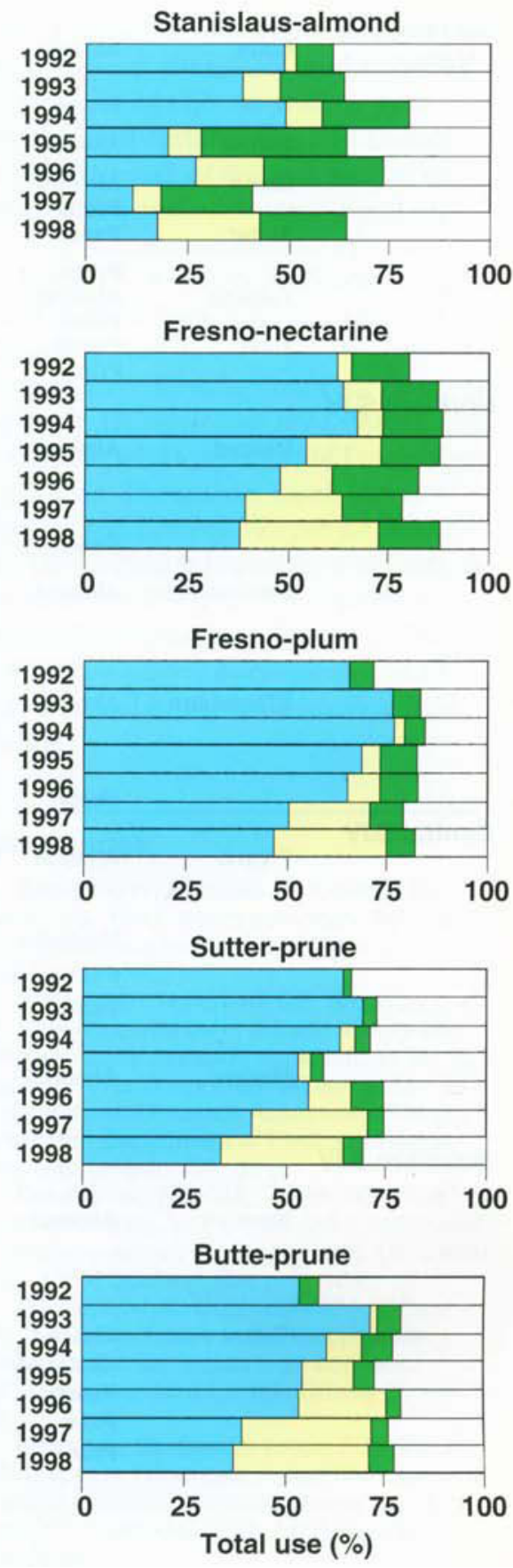

Fig. 3. Relative amounts of planted area in almond and stone fruit orchards that were treated during the dormant season or at bloom, for counties with largest planted areas. "Other chemicals" are nearly all pyrethroids, but also include carbamates and endosulfan. "Reduced-risk" products include Bacillus thuringiensis, spinosad and dormant oil without another insecticide.

\section{Current OP use and reductions}

In each year from 1992 to 1998 , a - larger percentage of the area of stone fruit orchards was treated with dormant applications of OPs than almond orchards (fig. 2). However, in both stone fruit and almond orchards, the percentage of area treated with OPs declined between 1992 and 1998.

For selected counties and crops, figure 3 shows a pest management perspective of the relative amount of planted area that was treated with ei- 


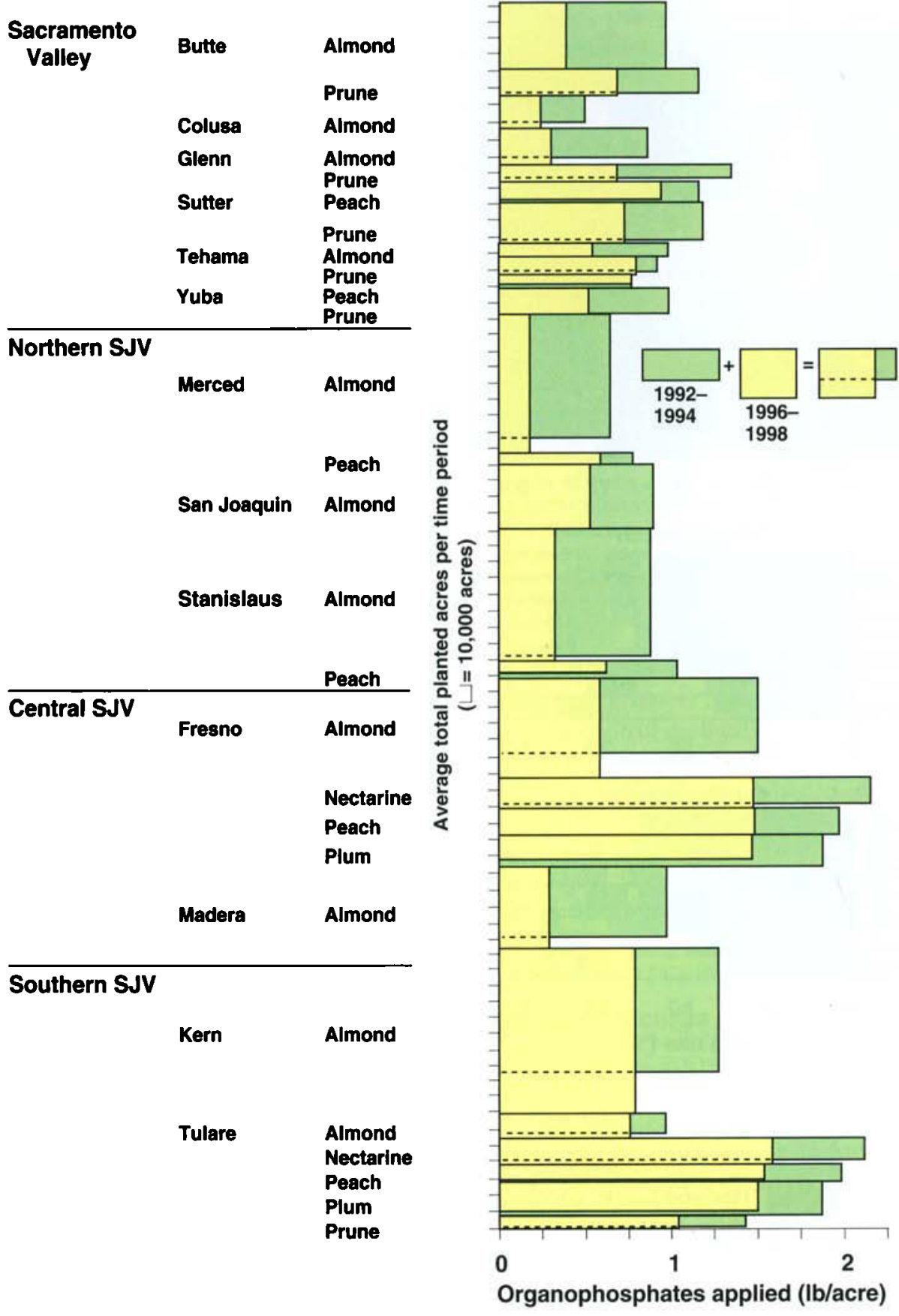

Fig. 4. Amount of OPs applied during dormant season in counties with at least 6,175 acres of almond, peach, prune, plum or nectarine. The 1996-1998 period overlays the 1992-1994 period, showing reductions in use from the earlier to later period. The portion below the dotted line in the yellow boxes refers to nonbearing acreage for 1996 to 1998. The area of each rectangle = base $\times$ height $=$ "Ib/acre" $\times$ acres $=$ total pounds for that crop in that county, where "total pounds" is yearly average over a 3-year period of OPs applied during the dormant season. "Pounds per acre" is "total pounds" divided by the yearly average total planted acres.

ther dormant-season OPs or the alternative treatments for each year of the study. The three highest years of use of dormant-season OPs typically occurred in the 1992 to 1994 period, then. declined. For example, in Merced
County almond orchards, a yearly average of $30 \%$ of the planted area was treated with OPs during the 1992 to 1994 period, whereas only $9 \%$ was treated in the 1996 to 1998 period (fig. 3). In Merced County there was an av- erage of 76,000 acres of almond orchards in the early period and 87,000 acres in the later period (fig. 4). During the 1992 to 1994 period, 0.63 pounds of active ingredient were applied per acre, when averaged over the entire planted area; this figure dropped to 0.17 pounds per acre during the later period (fig. 4). The amount of OPs applied to Merced County almonds in the earlier period is therefore approximately 48,000 pounds $(0.63 \mathrm{lb} /$ acre $\times$ 76,000 acres $=48,000 \mathrm{lb}$ ) (fig. 4). Continuing the calculation, in Merced County, dormant-season OPs applications on almond orchards decreased $70 \%$ during the study period.

On the whole, the total amount of OPs applied during the dormant season in both almond and stone fruit orchards decreased between $12 \%$ and $70 \%$, depending on the county-crop, in all but two county-crop combinations (prune orchards in Tehama County and almond orchards in Tulare County) (fig. 4). Although figure 4 shows modest declines in the pounds of OPs per acre in these two county-crop combinations, the increases in acreage resulted in no change in the total pounds of OPs. Somewhat similarly, although there was no decline in the pounds of OPs per acre in peach orchards in Yuba County, there was a decline in the total amount applied because acreage decreased.

Growers treat nonbearing orchards less frequently than bearing orchards, presumably because there is no fruit to be damaged. Consequently, in those county-crops with an increase in acreage (nonbearing acres shown in fig. 4 below the dotted line in the white rectangle), some of the decline in OP use on a per-planted-acre basis was presumably due to new plantings. Whether OP use will increase as these orchards come into bearing is unknown.

Despite the reductions in use of dormant-season OPs, large quantities of OPs were still applied in dormant orchards. In the 1996 to 1998 period, approximately 230,000 pounds of dormant-season OPs were applied yearly on the almond orchards in 11 counties. Similarly, in the 16 county- 
stone fruit combinations, approximately 230,000 pounds of dormantseason OPs were applied yearly.

The year-to-year fluctuations in OP use (fig. 3) are an indication that many factors affect pesticide use. These factors include the frequency of rain, which influences whether or not growers can move equipment into their fields to apply pesticides; grower's finances and relative prices of the crop and pesticides; and environmental conditions that either favor or deter an increase in the pest population.

\section{Increase in pyrethroids}

Overall, growers did not replace dormant-season OPs with in-season OPs. For example, there was no increase in the amount of area treated with OPs during the growing season (data not shown).

For both stone fruit and almond orchards, the decline in area treated with dormant applications of OPs was accompanied by an increase in area treated with dormant-season pyrethroids (fig. 2). However, particularly in 1997 and 1998, a higher percentage of planted area with stone fruit orchards was treated with pyrethroids than in almond orchards. Some pyrethroids are less expensive than OPs and the other alternatives. In both almond and stone fruit orchards, the percentage of area treated with dormant applications of OPs decreased and the area treated with pyrethroids increased from 1992 to 1998 (figs. 2 and 3). Likewise, in almond orchards, a substantial area was not treated with either OPs or with other conventional pesticides, and the area of almond orchards treated with reduced-risk alternatives increased (fig. 3). Use of either $B$. thuringiensis or oil without a conventional insecticide increased in almond orchards. In contrast, in stone fruit orchards there was no overall change in the percentage of area treated with any of the reduced-risk products or in which there was no dormant treatment.

In contrast to almonds, we did not observe a trend toward increasing use of reduced-risk alternatives in stone fruit orchards. This may be due to several factors. There are differences in cosmetic requirements for nectarine, peach and plum fruits in comparison to almond and prune fruits. Also, there are two additional pests of concern in plums and prunes: the leaf curl plum aphid and the mealy plum aphid, both of which are controlled by a dormant OP application. Finally, educational outreach was perhaps greater for almonds during this time because this crop covers more primary areas of concern for OP contamination of surface water.

\section{Pesticide use reports}

The California pesticide use reports (PUR) are supposed to be a census of all pesticide use in production agriculture, rather than a sampling. However, the extent of underreporting is unknown. Nonetheless, it is extremely unlikely that there has been a systematic decrease in reporting OPs, but not other pesticides. The data provide overwhelming evidence of a systematic decrease in use of dormant-season OPs on almond and stone fruit orchards in California (fig. 4). This is particularly noteworthy because there are few documented examples of declines in pesticide use on other crops.

California has the best agricultural pesticide use database in the world. Although the database contains much information, utilization of the PUR presents challenges. The PUR database has errors; the impact of those errors can be minimized by using the individual applicator records, a datacleaning program, and a careful examination of the results, as was done here. However, use of the individual applicator records requires computer expertise. For IPM researchers, the greatest limitation of the PUR is that it does not contain information on the target pest(s), the amount of pest pressure, or the susceptibility and intended use of the crop. Nonetheless, the PUR does provide a wealth of information about trends in chemical control programs.

Additional information on monitoring for insects, and the use and cost of the alternatives, is available on the UC IPM Web page (www.ipm.ucdavis. edu/WATER/OPCALC/). Greater use of reduced-risk alternatives to dormant-season chemicals could further reduce use of OPs, as well as pyrethroids and carbamates, and thereby reduce the risk of environmental contamination and additional regulation.

L. Epstein is Associate Professor, Depart ment of Plant Pathology, UC Davis; S. Bassein is Statistician, Data Analysis and Presentation, Berkeley; and F.G. Zalom is Director, UC Statewide IPM Project, and Entomologist, Department of Entomology, UC Davis. The authors thank Larry Wilhoit and Edward Morgan for providing the California Department of Pesticide Regulation's Pesticide Use Report computer files, and Janet C. Broome of UC $S A R E P$ for helpful discussions. Funding was provided by the UC Statewide IPM Project.

\section{References}

Barnett WW, Edstrom JP, Coviello RL, Zalom FG. 1993. Insect pathogen "Bt" controls peach twig borer on fruits and almonds. Cal Ag 47(5):4-6.

Bennett KP, Nordmark CE, Schuette J, et al. 1998. Occurrence of aquatic toxicity and dormant-spray pesticide detections in the San Joaquin River Watershed, Winter 1996-1997. Environmental Hazards Assessment Program EH 98-02. Department of Pesticide Regulation, Sacramento, CA. 32 p.

Bentley WJ, Rice RE, Zalom FG. 1999. Insects and mites. In: Flint ML (ed.). Integrated Pest Management for Stone Fruits. UC DANR Pub. 3389, Oakland, CA. p 51-109.

Domagalski JL, Dubrovsky NM, Kratzer CR. 1997. Pesticides in the San Joaquin River, California-Inputs from dormant sprayed orchards. J Environ Quality 26:45465.

Epstein L, Bassein S, Zalom FG, Wilhoit LR. (In press.) Changes in pest management practice in almond orchards during the rainy season in California USA. Ag, Ecosystems and Envir.

Hendricks LC. 1995. Almond growers reduce pesticide use in Merced County field trials. Cal Ag 49(1):5-10.

Rice RE, Jones RA, Black JH. 1972. Dormant sprays with experimental insecticides for control of peach twig borer. $\mathrm{Cal} \mathrm{Ag}$ 26(1):14.

Zalom FG, Van Steenwyk RA, Bentley WJ, et al. 1998. Insects and mites. In: UC IPM Pest Management Guidelines for Almonds. UC DANR Pub. 3339, Oakland, CA. p B1-B21.

Zalom FG, Stimmann MW, Arndt TS, et al. (In press.) Analysis of permethrin (cis-and trans-isomers) and esfenvalerate on almond twigs and effects of residues on the western orchard predator mite, Galendromus occidentalis Nesbitt. Env Entomology. 